\title{
PRACTICAL TERRESTRIAL LASER SCANNING FIELD PROCEDURE AND POINT CLOUD PROCESSING FOR BIM APPLICATIONS - TNB CONTROL AND RELAY ROOM 132/22KV
}

\author{
M. H. Zakaria ${ }^{1}$, K. M. Idris ${ }^{1}$, Z. Majid ${ }^{1}$, M. F. M. Ariff ${ }^{1}$, N. $\operatorname{Darwin}^{1}$, M. A. Abbas ${ }^{2}$, K. Zainuddin $^{2}$, R. A. Shukor ${ }^{3}$, M. A. Aziz ${ }^{1}$ \\ ${ }^{1}$ Geospatial Imaging and Information Research Group, Faculty of Built Environment and Surveying, Universiti Teknologi Malaysia, \\ 81310, Skudai, Johor, Malaysia-mdhafizzakaria@gmail.com, khairulnizami@utm.my, zulkeplimajid@utm.my, mfaridma@utm.my, \\ norhadija2@utm.my, mafiq5039@gmail.com \\ ${ }^{2}$ Centre of Study for Surveying Science \& Geomatic, Faculty of Architecture Planning \& Surveying, Universiti Teknologi MARA \\ Perlis Branch, 02600 Arau Perlis - mohdazwanabbas@ gmail.com, khairul760@ perlis.uitm.edu.my. \\ ${ }^{3}$ Wireless Communication Centre (WCC), Universiti Teknologi Malaysia, 81310, Skudai, Johor, Malaysia-rashidah-as@utm.my
}

KEY WORDS: Terrestrial Laser Scanning, Point Cloud, Asset Mapping, 3D Model, Building Information Modelling

\begin{abstract}
:
Thetransmissionmain-intakeisoneofthemostimportantunitstosupplytheelectricityinsomeplace. Each transmission main-intake has its own utilities and assets according to each function and type. During thistime, eachtransmissionmain-intake structureandtheassetsinside only can be monitored by 2-dimensional (2D) model other than on-site visits. This study is conducted to produce a 3- dimensional (3D) model of the building's internal structure and assets that will facilitate and further improves the monitoring process, maintenance and documentation of assets for certain parties for further uses in form of 3D Building Information Modelling (BIM). This study was conducted in Tenaga Nasional Berhad (TNB) control and relay room at PE61 132/22KV Transmission main-intake building of Universiti Teknologi Malaysia (UTM) using Terrestrial Laser Scanner (TLS) Topcon GLS-2000 model. At the data processing stage, several series of software was used to complete the 3D model. Scanning process will generate an indoor point cloud of the building. The result from the data processing stage is more focused on the $3 \mathrm{D}$ internal model of the building that has been digitized from the point cloud data. The 3D model will be able to show the internal structure of buildings and the assets more clearly. In order to complete the 3D BIM, information regarding the assets was added.In this study, the efficiency of TLS Topcon GLS-2000 for 3D BIM was determined in term of its accuracy by comparing with the distometer. The accuracy for scanned data from TLS were compared with the distometer by using root mean square error (RMSE) formula, and the accuracy is only $\pm 0.004 \mathrm{~m}$.
\end{abstract}

\section{MANUSCRIPT}

\subsection{Background}

Thedemandandneedsfor3-dimensional(3D)models are growing and expanding rapidly in a variety of fields nowadays. 3D models are widely used in a variety of field. This application includes asset management, environmental modeling, reverse engineering, city planning, cultural heritage, and also piping (Fauzi, 2010). The use of 3D functions is particularly powerful in visualizing urban and built environments, giving the option to deliver the relevant information in comprehensive form. Digital 3D models are cheaper to build and can be easily stored and retrieved when it is needed. Visualization of these models allows the user to get the realistic view of the structures than graphic based object models. The 3D digital models become important solutions as the high demand in presenting the world more realistically (Mngumi and Ruther, 2004). Over the past few years, it has become evident that 3D technology using Terrestrial Laser Scanner (TLS) is the most appropriate technique for documentation an objects, topographic plans and more. TLS is also called an active remote sensing system because no additional personnel are needed to hold a ranging pole or to place targets for measuring surfaces, which are not practical if the survey has to be done on hazardous areas such as landfall sites. Other advantages of laser scanning are better quality of the results in terms of accuracy and precision of final result, one-man survey concept, no interference with construction and operations activities and simple and easy equipment operating and data processing (Ramli, 2010).

\subsection{Terrestrial Laser Scanning}

The popularity of Terrestrial Laser Scanner (TLS) has been introduced into a field of surveying and has increased dramatically especially in producing the 3D model of the building. Other than the ability to collect data of land and object of various shape and sizes in a quick way, it is also very useful to obtain high accuracy measurement while include the images in real time(Abellan et al., 2009)TLSisoneofinstrument thatcan provide efficiency in surveying. TLS can also provide data at unreachable place. Even though the shape of the building is complex yet the TLS able to produce detail of the 3D point cloud. Instead of measuring the complex design by conventional method, which is using the distometer, TLS is the new method that can be implemented to provide the accurate dimension of complex design for each parcel (Arayici, 2007).

The conventional system provide information in single point only compare to TLS which able to record huge numbers of point. Moreover, TLS gives more advantages in understanding the scanned data especially when dealing with complex building. The TLS is not using any physical method while collecting the data. TLS is using remote sensing technique because individual to hold the sign of the target in process of collecting data is not required (Froclich and Mettenleiter, 2004). Most of the different industrial sector such as engineering and architecture today require the 3D model of building (Abdul Rahman, Stoter, Nordin, 2005). The laser scanner can gives the data with full of accuracy and increase the speed of 3D data acquisition(Aziz et al., 2016). 
The scanner can record thousands of points per second and each point has their location coordinates and elevation information. TLS can go for the rays up to 4000 meters and rated to have their best accuracy at distances out to 130 meters which means, it is capable to scan the whole areas and all object within the distance. The ray also safe for the eyes, and have multi target to take the reading (Sepasgozar et al., 2014)

Furthermore, the application field that involved with the laser scanner are topography, industrial, engineering and also in forensic field. The market of laser scanners for terrestrial applications has developed quite successfully and the laser scanners are seen as one of the surveying instruments that meet the requirements of industrial applications (Froclich and Mettenleiter, 2004). At first, the invention of the laser scanning is just suitable for short-range only. However, the uses of this laser scanning is keep increasing, and have pushed the development of the technology to invent the new updatedlaserscanner. Thus, themidrange and long- range laser scanner has been introduced (Pukanska, 2012).

\subsection{Building Information Modelling (BIM)}

Building Information Modelling (BIM) has became the international benchmark for efficiency in Achitectural, Engineering, and Construction (AEC) (Macdonal, 2012). Series of study has also reveal BIM is having the potential to significantly change and improve perfomance and documentation in AEC industry (Thomson et al., 2013). BIM is a process involving the generation and management of digital representations of physical and functional characteristics of a particular building. Building information models (BIMs) are files which can be exchanged to support decision-making about a certain building (Mahdjoubi et al., 2013). BIM is emerging as the industry standard approach to the modelling and management of building lifecycle; from design and construction to maintenance, and demolition. 3D laser scanning and BIM technologies have offered new possibilities for capturing, mapping and analysis of building information (Geodert and Meadati, 2008).

Conventional method to produce 3D model for BIM is by measuring the distance of each dimension in the building using distometer. It has been used widely to measure the distance because of its size, which is small and handy. But it also has the weaknesses. The reading from distometer cannot be recorded, and all the measurement needs to be written manually, and it is also unable to provide the 3D model of the building. Thehandling of this instrument is same as the application of total station or Theodolite. For this study, the Terrestrial Laser Scanner which is Topcon GLS-2000 was used to produced 3D BIM

\subsection{Asset Documentation}

Asset documentation has undergone changes which is parallel with technological advancement. However, people still relate asset documentation with the conventional recording method. This method is called recording and filing system. This system operatesbya person who will record any utilities such as switches, fans, lights, wiring system and others that are available on a building using check-form. Check-forms method to document assets is a traditional method,whihuses papers and folders in hardcopy style for documentation. There are information regarding assets that are visually displayed in form of papers. This method is tedious as there is need to re-do the documentation of assets if there are errors done such as miscalculation of quantity of assets and their informations such as vendors name and addresses and so on.
Furthermore, this method is prone to risk of losing of paper hardcopies. The final product of this research which is a 3D model with asset information can serve as a guideline for asset documentation

\section{METHODOLOGY}

The research methodology is divided into 4 phases. Each phase has to be done and carry out with the rightmethod toget the best results. Figure 1 shows the flow chart of the methodology of this study. Phase one (1) discussed about the literature review, problemstatements, research objectives and the scope of the study to get as much information as possible about the research to be done to facilitate the work process for this study. Additionally, before the study was conducted, work planning was the most important thing to do to ensure that the research was successful. This study requires the right tools and software to produce quality results. The study area covered the indoor control and relay room located at PE 61 132/22KV Transmission Mainintake,UTM,Johor

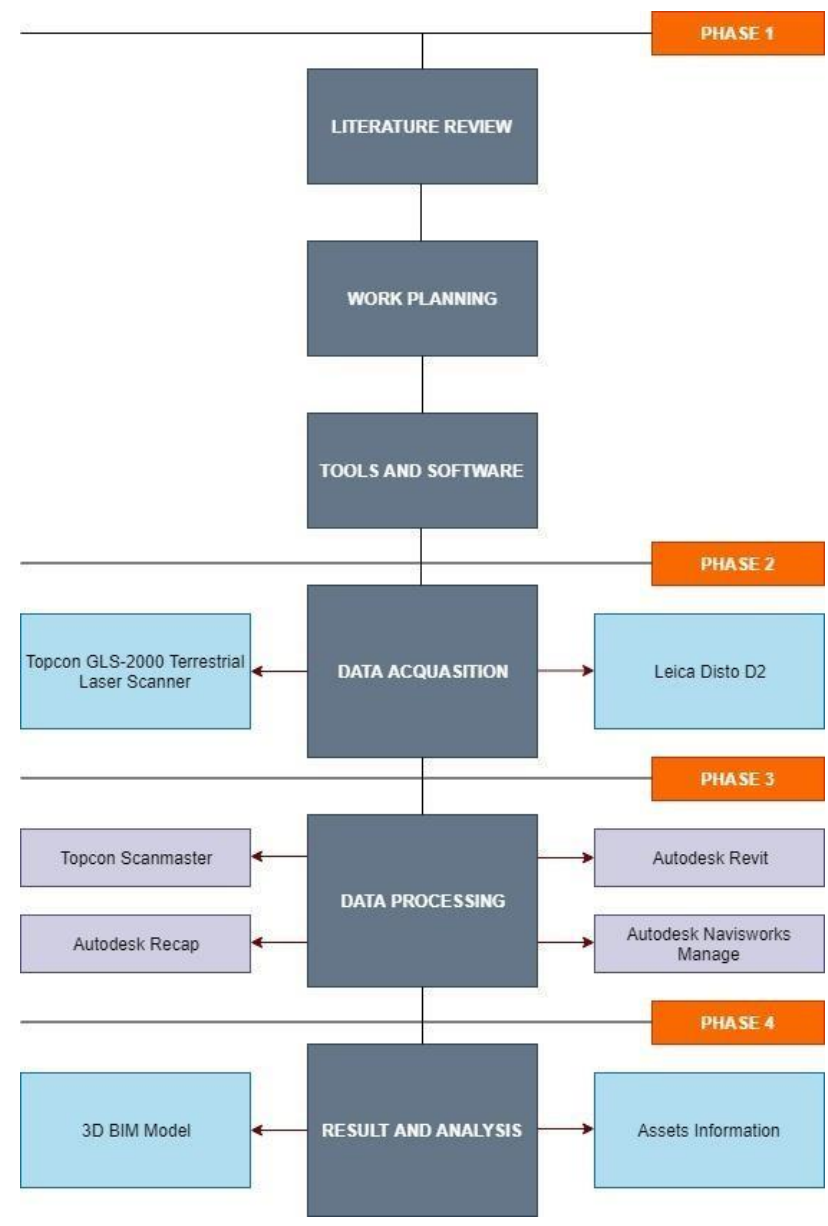

Figure 1: Methodology of study

\subsection{Data Acquisition}

Before data collection proceed, the determination of scanned area needs to be done to ensure that area is suitable for this study while survey planning is to define the uses of scanner, position of scanner and target position. 
Data acquisition needs to be done carefully so the data obtained can be used for processing. Point cloud data acquisitions were donebyusing Topcon GLS-2000 Terrestrial Laser Scanner. All the collected point cloud data then were compared with the data dimensions collected by Leica Disto D2 as the conventional method. The flow of methodology for Topcon GLS- 2000 is shown in Figure 2. All these flows were discussed in following points.

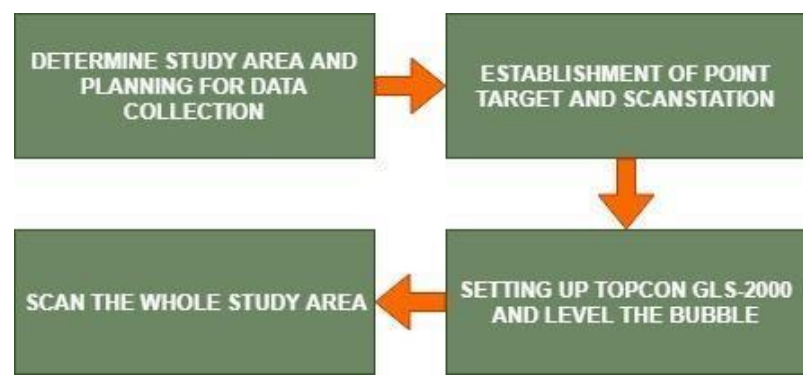

Figure 2: GLS-2000 field procedure

The TNB indoor control and relay room located at block PE61 $132 / 222 \mathrm{KV}$ transmission main intake for Universiti Teknologi Malaysia as shown in Figure 3. A plan of survey area was sketch on paper to determine the location of scanner and the target (Figure 4). It is to ensure that all the information and detail of the building was covered. This research used only one scanner to scan the whole survey area so it needs to move to another scan station to scan the next part of the area. In this survey, 15 scan stations were needed to cover the whole area. In this study, target by 'common features' were selected for the scan process. The placement of targets should be considered with the position of scanner because it acts as a control point for point cloud registration. At least three targets should be clearly seen by each other and can be scanned by scanner for each station.

Topcon GLS-2000 must be set up and its bubble must be adjusted. Topcon GLS-2000 was placed on a tripod during scanning process to ensure the stability of the scanneritself. The bubble was adjusted untilbelow30 seconds. It must be done for every station.

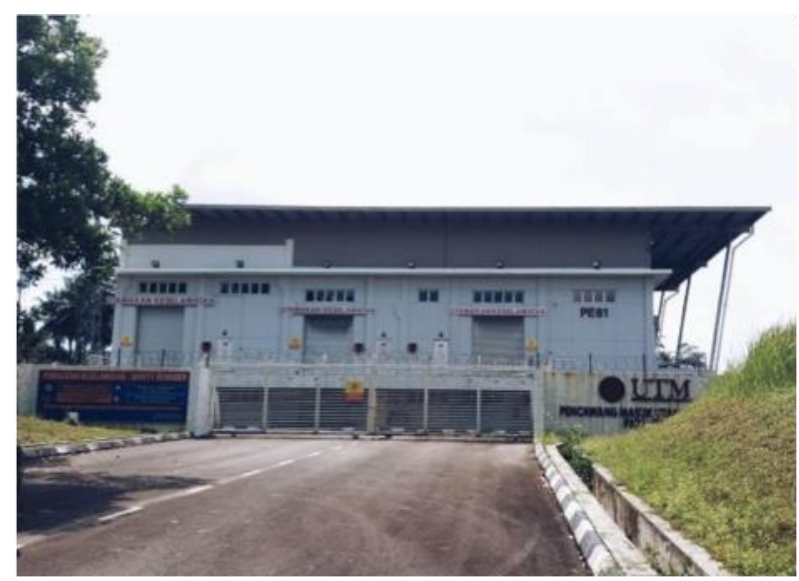

Figure 3: PE61 132/22KV Transmission Intake, UTM Johor Bahru, Malaysia

The scanning procedures can be proceeds after the file project was created. Common features targets have been used and scan resolution is setat low resolution $(12.8 \mathrm{~mm})$ as the site area is indoor area and falls in range of less 20 meters. Next, scanning is performed on the entire site. Field-Of- View will be set as 'target all' so that scanning goes 360 .

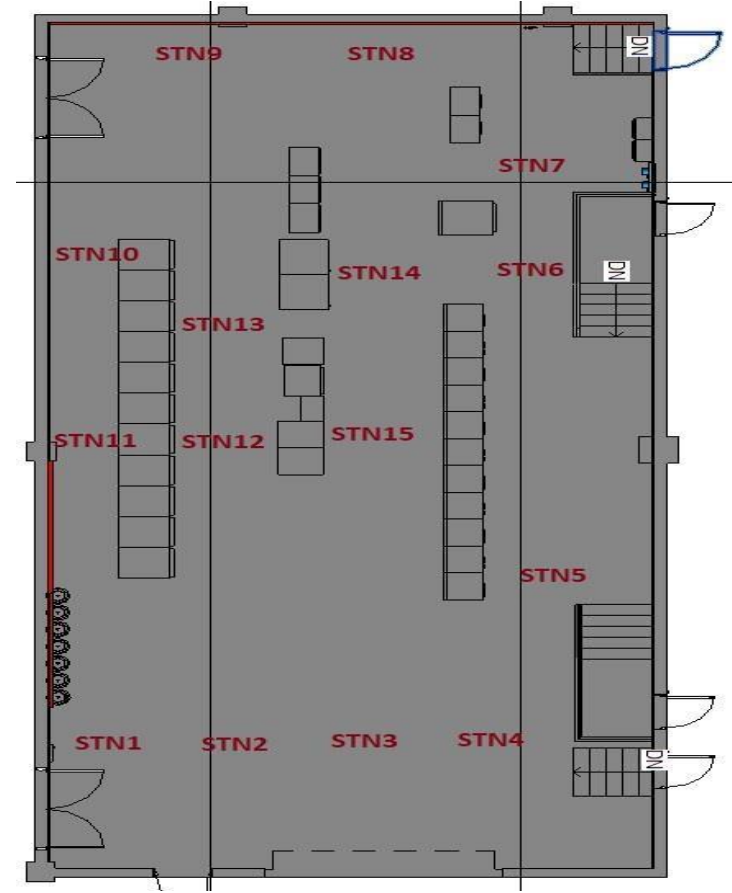

Figure 4: Distribution of TLS stations

The scanning on low resolution takes about 10 to 15 minutes. The overall data acquisition process take 4 hours for 15 stations including the process of setting up the laser scanner at each scan station. The Image acquisition was combining with the point cloud acquisition so that the data have the photorealistic value. The data given is point cloud, and an image with coloured point cloud. After the scanning process completed, the scanned data can be seen automatically at the screen window on the Topcon GLS-2000. Only then, the scanner can be moved to the next station. The standard set up must be done before moves the laser scanner. It is a must to ensure the new station folder has been created up toavoid the overlay data. All the raw data then were downloaded to the computer for data processing.

\subsection{Point Cloud Processing}

This phase discuss about data processing procedures and softwares used for dataprocessing. The right choice of software in data processing is crucialtotheexactandnecessaryresultsinthis study. There are four (4) type of software being used in this study such as Topcon Scanmaster, Autodesk Recap, Autodesk Revit and Autodesk Navisworks Manage. These software were used to process data in the form of point cloud with images acquired by the terrestrial laser scanner until generation of 3D BIM mode.

All the point clouds data acquired from Topcon GLS- 2000 need to undergo registration process where all sets of scans are combined into one complete model. This process is to match point clouddatafromdifferent station to tied up together. This research has 15 different position of the scanner, so registration process is a must to combine all the point cloud data to be in one image of the study area (Figure 5). To complete to registration process, Topcon Scanmaster software was used. After the registration process was done, the point cloud data was exported into '.las' format so it can be imported and process in Autodesk Recap software. 


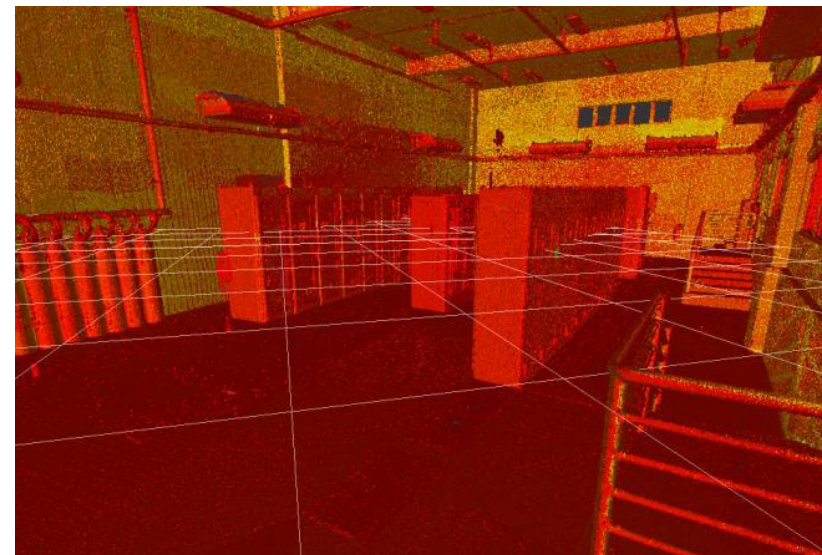

Figure 5: Registered point cloud data

Noise filtering is done where reduction of points and unnecessary points are remove from the point cloud data. The unwanted point cloud data that can disturb the measuring and modelling process needs to be removed. It is because the measuring process is an important process to get the dimensions of the building and the assets inside the control and relay room. Hence, cleaning and filtering process for Topcon GLS-2000 data was done by using Autodesk Recap. Thus, the indoor building can be viewed clearly as shown in Figure 6. This process transformed the data ready for export into other software for the 3D BIM generation process, where the data is exported as a '.rcp' file (Recap file format).

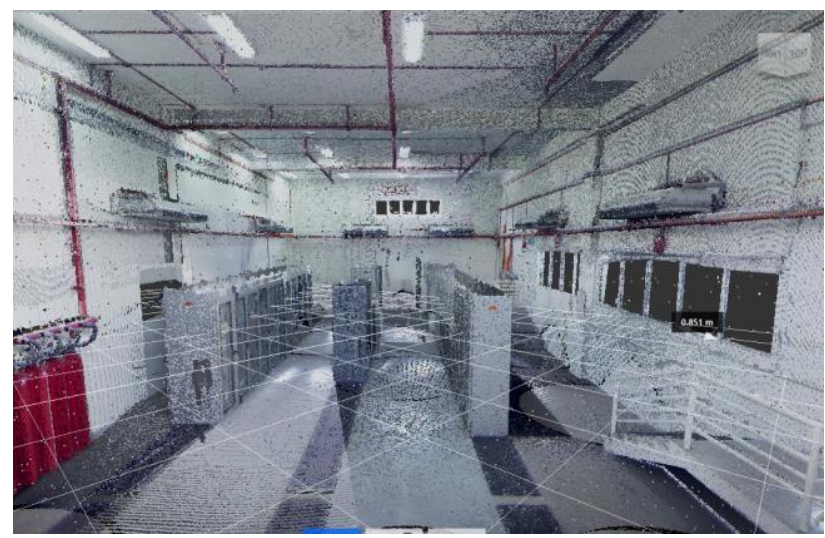

Figure 6: Cleaned registered point cloud in Autodesk Recap

Point cloud model are then export into Autodesk Revit software to construct an architectural design of 3D model 132/22kV Control and Relay Room. The cleaned point cloud data was imported into the Revit through 'Point Cloud tool'. Architectural designs were produce such as walls, doors, panels box, stairs, and others including building internal assets base on the point cloud model. Figure 7 show that the 3D model that had been produced by Autodesk Revit. The 3D model then exported to '.rvt' file (Revit File Format).

After 3D architectural model was constructed in Revit, it is the exported into another software called Autodesk Navisworks Manage for input of information regarding 3D model so that 3D BIM model can be generated. Information that was inserted such as server panels name and models, type of rack, type of tripping device, battery fuse and others. Figure 8 show attributes registration process in Autodesk Navisworks Manage.

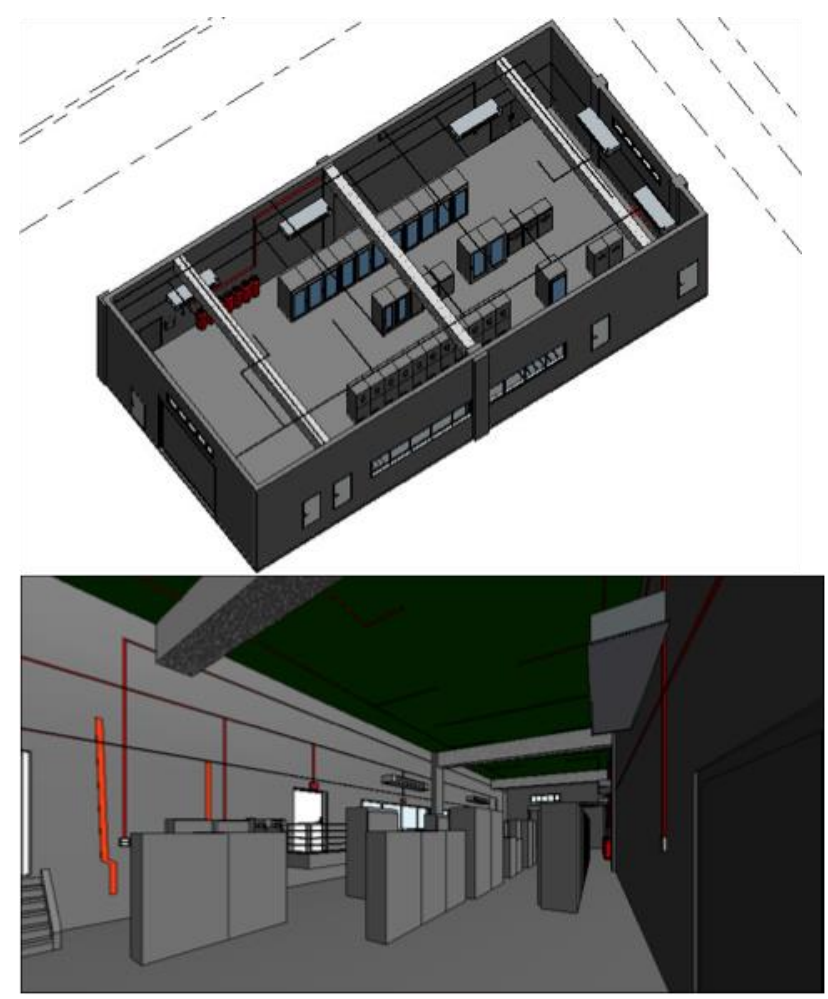

Figure 7: 3D model of 132/22KV Control and Relay Room

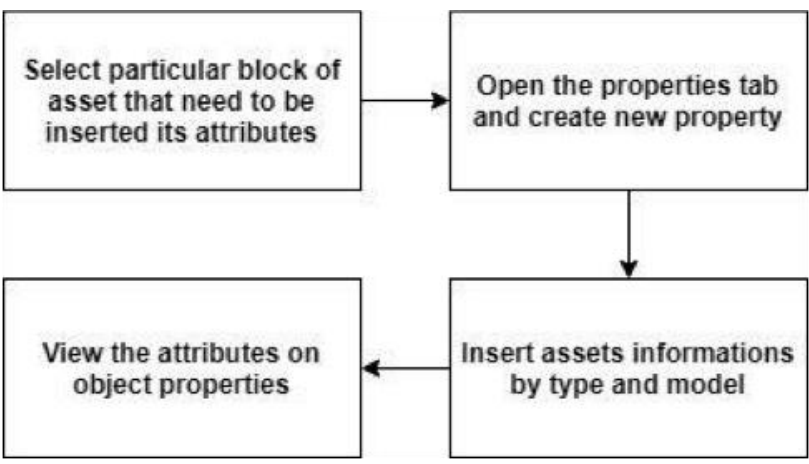

Figure 8: Attributes registration process

\section{RESULT AND ANALYSIS}

This section discussed the final results of 3D BIM model obtained using Topcon Scanstation, Autodesk Recap, Autodesk Revit, Autodesk Navisworks Manage software and Topcon GLS-2000 Terrestrial Laser Scanner. The 3D BIM model and Accuracy analysis was made to study the suitability and realibility of TLS and the softwares used for 3D Building Information Modelling at 132/22KV Control and Relay Room. Meanwhile, the 3D modeling analysis consisted of measurement analysis between Terrestrial Laser Scanning and Distometer. The results were compared for accuracy evaluation.

The completed 3D BIM models obtained from this study are shown in figure 15 , while the objects and its attributes available in the $132 / 22 \mathrm{KV}$ Control and Relay room are shown below in Figure 9, Figure 10 and Figure 11. Together with the objects are the asset attributes in properties tab shown next to the objects 


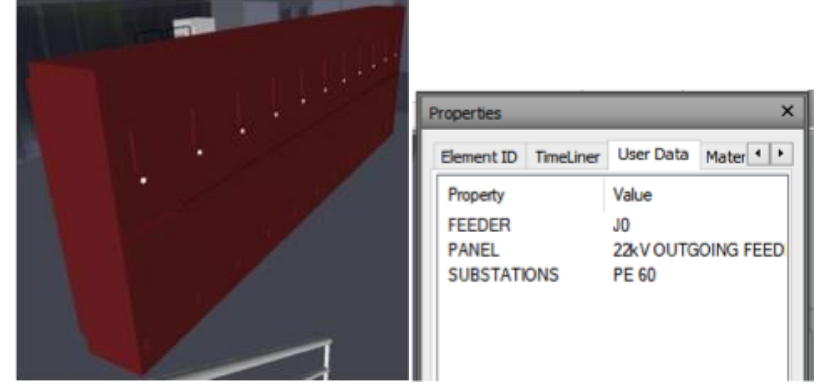

Figure 9: The 22kV Feeder Panel and its Attributes

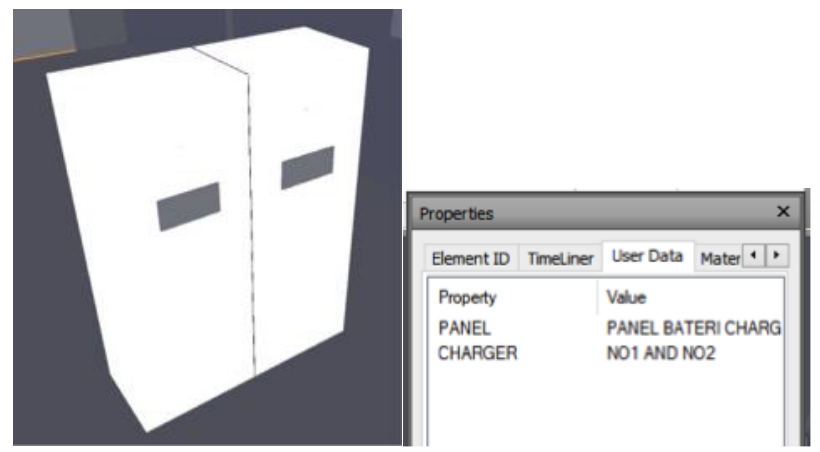

Figure 10: Battery Charger Panel and its Attributes

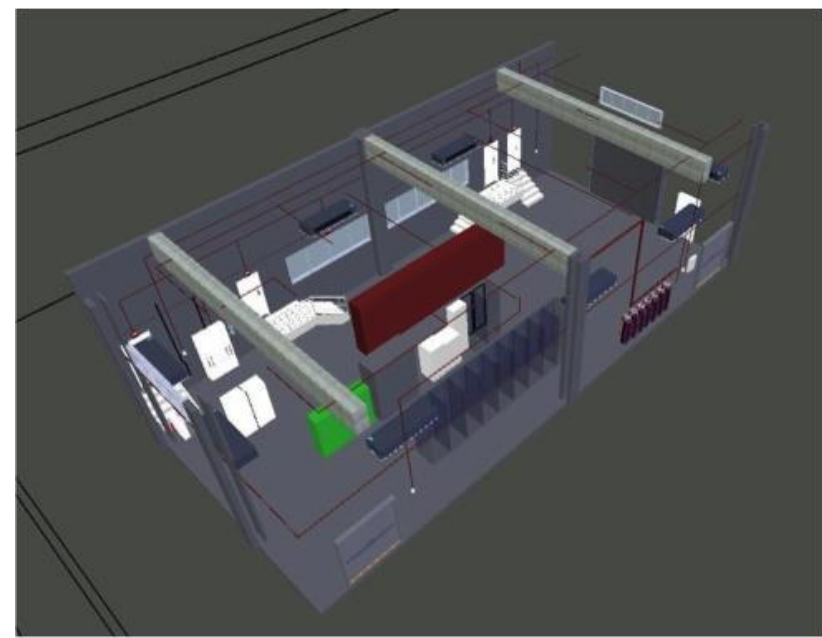

Figure 11: Complete3DBIMModelof 132/22KVControland Relay room

The analysis for this study includes measurement comparison between laser scanning measurements against measurements using distometer, A total of 15 distance of objects were compared The analysis was made to compare the accuracy of measurement and determine the suitability of the TLS 3D BIM Modelling and the best technique that should be used in 3D BIM's. The comparison was made based on the same objects, and at the same point. Table 1 shows the point of distance measurement result for two different techniques of TLS and Distometer. From the table 1, there were a few things can be concluded for measurement of the objects in the 132/22KV Control and Relay room. It shows only slightly different between the distance measurements. Both laser scanner and distometer gave measurement until millimeter level. The highest measurement difference between Topcon GLS-2000 TLS and Leica D2 Distometer was on height of Terminal Unit Panel with $0.009 \mathrm{~m}$. While the lowest measurement difference were the height of Roller Shutter Door with $0.001 \mathrm{~m}$. The maximum difference of dimension from TLS and distometer is because of human error during measurement process between two points or error during cleaning and filtering phase. While the minimum difference of dimension from TLS and Distometer is because of the TLS ability to give more accurate position up to millimeter level at a certain point. The RMSE value on the Table 1 was to compare the error between TLS with Distometer. The RMSE value is only $\pm 0.004 \mathrm{~m}$. According to the distance comparison and the RMSE value, it is proven that laser scanning method was accurate and sufficient to produced reliable virtual detailed 3D visualized model which target object consists of complex, large and small features. The accuracy of laser scanning was very close to the value from the Distometer. The difference was only at millimeter level and it is acceptable for modelling the 3D BIM.

Table 1: Comparison of distances between terrestrial laser scanning and distometer.

\begin{tabular}{|c|c|c|c|c|}
\hline Items & Dimension & $\begin{array}{r}\text { Topcon } \\
\text { GLS-2000 } \\
\text { TLS(m) } \\
\end{array}$ & $\begin{array}{c}\text { Leica D2 } \\
\text { Distometer } \\
(\mathbf{m})\end{array}$ & $\begin{array}{l}\text { Differences } \\
\text { (m) }\end{array}$ \\
\hline \multicolumn{5}{|l|}{$22 \mathrm{kV}$} \\
\hline \multirow{3}{*}{$\begin{array}{l}\text { Server } \\
\text { Panel }\end{array}$} & Width & 0.622 & 0.625 & 0.003 \\
\hline & Length & 0.566 & 0.561 & 0.005 \\
\hline & Height & 2.264 & 2.256 & 0.008 \\
\hline \multicolumn{5}{|l|}{$132 \mathrm{kV}$} \\
\hline \multirow{3}{*}{$\begin{array}{l}\text { Server } \\
\text { Panel }\end{array}$} & Width & 0.763 & 0.76 & 0.003 \\
\hline & Length & 0.702 & 0.705 & 0.003 \\
\hline & Height & 2.274 & 2.276 & 0.002 \\
\hline \multirow{4}{*}{$\begin{array}{l}\text { Remote } \\
\text { Terminal } \\
\text { Unit Panel }\end{array}$} & & & & \\
\hline & Width & 0.753 & 0.757 & 0.004 \\
\hline & Length & 0.752 & 0.749 & 0.003 \\
\hline & Height & 2.307 & 2.298 & 0.009 \\
\hline \multirow{3}{*}{$\begin{array}{l}\text { MDF Rack } \\
\text { Panel }\end{array}$} & Width & 0.602 & 0.606 & 0.004 \\
\hline & Length & 0.707 & 0.704 & 0.003 \\
\hline & Height & 2.122 & 2.127 & 0.005 \\
\hline \multirow{3}{*}{$\begin{array}{l}\text { Trippin } \\
\mathrm{g} \\
\text { Device }\end{array}$} & Width & 0.183 & 0.18 & 0.003 \\
\hline & & & & \\
\hline & Length & 0.2 & 0.204 & 0.004 \\
\hline \multirow{2}{*}{$\begin{array}{l}\text { Three Pin } \\
\text { Socket }\end{array}$} & Width & 0.151 & 0.145 & 0.006 \\
\hline & Length & 0.099 & 0.095 & 0.004 \\
\hline \multirow{4}{*}{$\begin{array}{l}\text { Roller } \\
\text { Shutter } \\
\text { door }\end{array}$} & & & & \\
\hline & Weidth & 3.199 & 3.195 & 0.004 \\
\hline & Height & 3.567 & 3.569 & 0.002 \\
\hline & & & RMSE & 0.004 \\
\hline
\end{tabular}

\section{CONCLUSION}

This paper has discussed the advantages of using TLS and few softwares to document an asset in the form of 3D Building information Modelling (BIM). Based from the case study shown above, it can be seen that TLS has helped to facilitate the overall process of collecting the data representing the scene, due to its ability in generating a high point density, rapid acquisition of $3 \mathrm{D}$ data and its good accuracy. Accurate measurements are very 
important in asset data capture because it can affect decisionmaking processespeciallyinrearrangement ofitemsinaroom need to be considered. With the help of suitable software available in the market, the process of developing such model to document assets the buildings has become easier.

The 3D BIM model was produced and accuracy analysis was carry out. Based on the 3D BIM model, it shows with the help of the selected software, the objective of this study can be achieved successfully. The accuracy analysis consists of the accuracy evaluation for TLS and distometer technique, and the RMSEvalueisonly $\pm 0.004 \mathrm{~m}$ which reinforcestheadvantages ofTLS in this study. This study would be beneficial for asset managers because they will not have to go back to the site to recheck the assets. Besides, the implementation of laser scanner in 3D BIM and asset data capture was proven as a faster method rather than conventional method that uses check form and photographic images.

\section{ACKNOWLEDGEMENTS}

The corresponding author highly acknowledge to Univsersiti Teknologi Malaysia for financial aid under UTM Transdisciplinary Research Grant TDR 6.1 (T2).

\section{REFERENCES}

A. Fauzi (2010). Aplikasi Perisian RapidformXOR Dalam Penjanaan Model CAD Tiga Dimensi. BEng.. Thesis. Universiti Teknologi Malaysia.

Mngumi, E. A., and Ruther, H. (2004). Solid Modeliing for Heritage Documentation. FIG W'orking week. May 22-27. Athens (Greece).

Nur Adlina bt Ramli. Three Dimensional Modeling of Historic Monument Using Topcon GLS- 1000. BEng.. Thesis. Universiti Teknologi Malaysia;2010.

Abellán, A., Jaboyedoff, M., Oppikofer, T., and Vilaplana, J., 2009. Detection of millimetric deformation using a terrestrial laser scanner: experiment and application to a rockfall event. NaturalHazardsandEarthSystemSciences, 9(2), 365-372.

Arayici, Y., 2007. An approach for real world data modelling with the 3D terrestrial laser scanner for built environment. Automation in construction, 16(6), 816-829.

Fröhlich, C. and Mettenleiter, M., 2004. Terrestrial laser scanning-new perspectives in 3D surveying. International Archives of Photogrammetry, Remote Sensing and Spatial Information Sciences, 36(Part 8), W2.

Abdul-Rahman, A. Stoter, J., and Nordin, A., 2005. Towards 3D cadastre in Malaysia. Paper presented at the Proceedings of the Joints International Symposium \& Exhibition on Geoinformation 2005 \& International Symposium on GPS/GNSS 2005 (ISG-GNSS 2005).

Aziz, M. A., Idris, K. M., Majid, Z., Ariff, M. F. M., Yusoff, A. R., Luh, L. C., and Chong, A. K., 2016. A study about terrestrial laser scanning for reconstruction of precast concrete to support QCLASSIC assessment. International Archives of the Photogrammetry, Remote Sensing and Spatial Information Sciences, 42,135-140.
Sepasgozar, S., Lim, S., Shirowzhan, S., and Kim, Y., 2014. Implementation of as-built information modelling using mobile and terrestrial lidar systems. Paper presented at the ISARC. Proceedings of the International Symposium on Automation and Robotics in Construction.

Pukanská, K. (2012). The application of terrestrial laser scanning for spatial visualization of laboratories of the BERG faculty. ACTA MONTANISTICA SLOVAC'A, /7(4), 341-347. Macdonald, J. A. 2012. A Framework for Collaborative Bim Education Acros the Aec Disciplines.

C. Thomson, G. Apostolopoulos, D. Backes and J. Boehm (2013). Mobile Laser Scanning ForIndoor Modelling. In : ISPRS Annals of the Photogrammetry Remote Sensing and Spatial Information Sciences, Volume 11-5/W2,2013 ISPRS Workshop Laser Scanning 2013, 11-13 November 2013,Antalya, Turkey.

Mahdjoubi, L., Moobela, C., and Laing, R. (2013). Providing realestate services through the integration of 3D laser scanning and building information modelling.Computers in Industry, 64(9), 1272-1281.

Geodert, J. D. and Meadati, P. 2008. Integrating Construction Process Documentation into Building Information Modeling. Journal Of Construction Engineering and Management. 134(7): 509-516

Revised August 2019 